\title{
Fatal acute pulmonary oedema after inhalation of fumes from polytetrafluoroethylene (PTFE)
}

\author{
C.H. Lee*, Y.L. Guo**, P.J. Tsai**, H.Y. Chang*, C.R. Chen*, \\ C.W. Chen*, T-R. Hsiue*
}

Fatal acute pulmonary oedema after inhalation of fumes from polytetrafluoroethylene (PTFE). C.H. Lee, Y.L. Guo, P.J. Tsai, H.Y. Chang, C.R. Chen, C.W. Chen, T-R. Hsiue. (CERS Journals Ltd 1997.

ABSTRACT: The cases of three patients with acute pulmonary oedema caused by inhalation of fumes from heated polytetrafluoroethylene (PTFE) in a plastic factory are described.

One patient died from profound hypoxaemia and shock shortly after admission, and the other two patients survived after medical treatment. This is the first report of fatal pulmonary oedema in a worker exposed to PTFE heated in a plastic extruding operation.

From this observation, it appears that inhalation exposure to pyrolytic products from polytetrafluoroethylene can cause fatal respiratory complications. Special precautions are warranted in this kind of operation to prevent workers from being exposed to these substances.

Eur Respir J 1997; 10: 1408-1411.

\author{
Depts of *Medicine and **Environmental \\ and Occupational Health, National Cheng \\ Kung University, College of Medicine, \\ Tainan, Taiwan ROC. \\ Correspondence: T-R. Hsiue \\ Dept of Internal Medicine \\ National Cheng Kung University Hospital \\ 138 Sheng-Li Road \\ Tainan 704 \\ Taiwan \\ Keywords: Acute pulmonary oedema \\ polytetrafluoroethylene \\ Teflon ${ }^{\circledR}$
}

Received: July 51996

Accepted after revision February 281997
Polytetrafluoroethylene (PTFE) or Teflon ${ }^{\circledR}$ has been widely used in industry as an electrical insulator and low friction material, due to its chemical stability and heat resistance. PTFE is considered nontoxic or physiologically inert, although at a temperature of $\geq 260^{\circ} \mathrm{C}$, PTFE fumes may be generated from the resin [1]. At a higher temperature, such as $\geq 350^{\circ} \mathrm{C}$, the fumes can be responsible for polymer fume fever [2-6]. Acute pulmonary oedema after inhalation of fumes from heated PTFE is very rare. Only a few cases have been reported in the literature [3, 7-9], and no fatal case has been described. In this report, we present an episode of inhalation of fumes from heated PTFE, which resulted in acute pulmonary oedema in three patients, including one fatal outcome.

\section{Case reports}

\section{Case No. 1}

A 43 year old man, was admitted to our emergency service at 02:00 h on September 13, 1995, with complaints of cough, dyspnoea, abdominal fullness, and vomiting for $6 \mathrm{~h}$. His wife reported that he had been in excellent health before the symptoms developed. He had worked as a moulder for 15 yrs in a plastic factory, where PTFE resins were melted and extruded to make rods. His regular working time was from 08:00 $\mathrm{h}$ to 17:00 h.

On September 12, the patient went home after work with a sore throat and headache. He developed shortness of breath, chest tightness, chills, nausea and vomiting approximately $2 \mathrm{~h}$ later. Because of aggravated dyspnoea, he was brought by his wife to the emergency service of our hospital.

Physical examination revealed a well-developed man, with pale face, cyanotic lips and extremities, general weakness and severe dyspnoea. His body temperature was $36.5^{\circ} \mathrm{C}$, pulse rate 125 beats. $\mathrm{min}^{-1}$, respiratory rate 40 breaths $\cdot \mathrm{min}^{-1}$, and blood pressure $92 / 48 \mathrm{mmHg}$. Auscultation of the lungs revealed diffuse crackles over both lung fields. The abdomen was soft, and bowel sound was normal.

An electrocardiogram was normal except for sinus tachycardia. A chest radiograph showed diffuse bilateral pulmonary infiltrates (fig. 1). A haemogram showed leucocytosis and haemoconcentration. The white blood cell (WBC) count was 50,600 cells $\cdot \mathrm{mm}^{-3}$; red blood cell (RBC) count was $6.28 \times 10^{6}$ cells $\cdot \mathrm{mm}^{-3}$; haemoglobin (Hb) $20.5 \mathrm{gm} \cdot \mathrm{dL}^{-1}$; and haematocrit $(\mathrm{Hct}) 60.6 \%$. Blood urea nitrogen (BUN) was $27 \mathrm{mg} \cdot \mathrm{dL}^{-1}$, creatinine 2.2 $\mathrm{mg} \cdot \mathrm{dL}^{-1}$, glutamic oxaloacetic transaminase (GOT) 38 $\mathrm{U} \cdot \mathrm{L}^{-1}$, glutamine pyruvic transaminase $(\mathrm{GPT}) 76 \mathrm{U} \cdot \mathrm{L}^{-1}$, creatinine phosphokinase $1,252 \mathrm{U} \cdot \mathrm{L}^{-1}$, and lactate dehydrogenase (LDH) 2,544 U.L-1. The levels of serum amylase, lipase, cholesterol and triglycerides were within normal limits. The arterial blood gas values recorded while breathing room air were: $\mathrm{pH} 7.30$, arterial carbon dioxide tension $\left(P \mathrm{a}, \mathrm{CO}_{2}\right) 5.0 \mathrm{kPa}(37.6 \mathrm{mmHg})$; arterial oxygen tension $\left(\mathrm{Pa}_{\mathrm{a}} \mathrm{O}_{2}\right) 4.8 \mathrm{kPa}(36 \mathrm{mmHg})$; serum bicarbonate $\left(\mathrm{HCO}_{3}^{-}\right) 18.7 \mathrm{mEq} \cdot \mathrm{L}^{-1}$; and base excess $-7.9 \mathrm{mEq} \cdot \mathrm{L}^{-1}$.

The patient was immediately treated with oxygen, fluid supply, inotropic agents, and antibiotics. Due to refractory hypoxaemia and deterioration of blood pressure, 


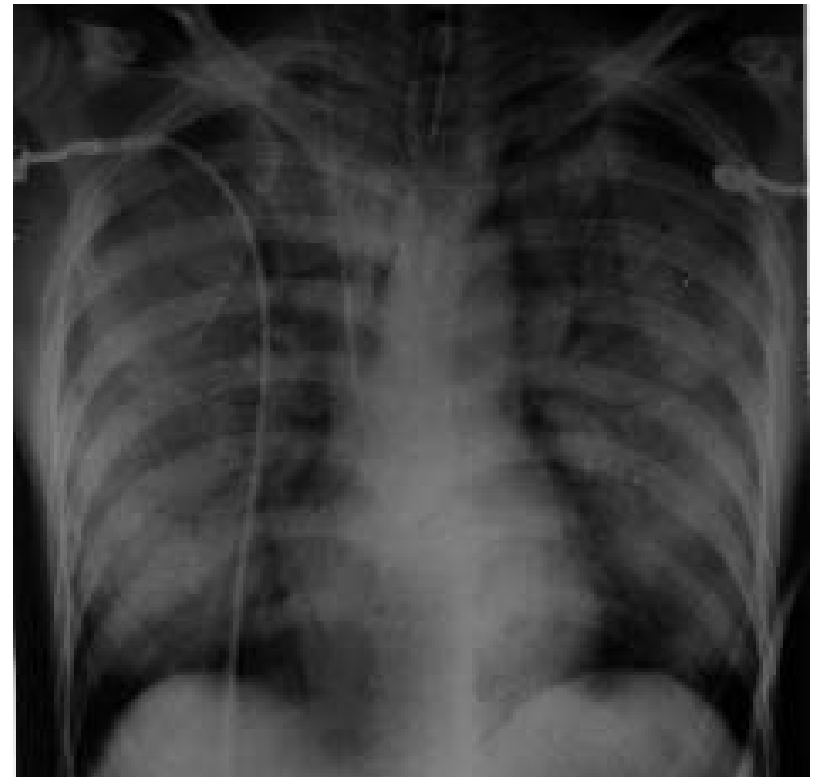

Fig. 1. - Chest radiograph of Case No. 1, taken in the emergency department, showing dense bilateral pulmonary infiltrates. The patient died a few hours later.

he was admitted to the intensive care unit and was intubated, mechanically-ventilated with $100 \%$ oxygen and 10 $\mathrm{cmH}_{2} \mathrm{O}$ positive end-expiratory pressure. However, he continued to have severe hypoxaemia, and developed ventricular tachycardia and undetectable blood pressure. He died at 07:00 h on September 13, $5 \mathrm{~h}$ after admission.

\section{Case No. 2}

This patient was a 37 year old man, who was the foreman of the plastic factory. In the early morning of September 13, 1995, he had chest pain, general weakness, shortness of breath, and fever with chill. Due to increasing dyspnoea, he sought medical care in another hospital, and was admitted to the intensive care unit with the impression of acute pulmonary oedema. He was then transferred to our hospital on September 16, upon notification of his colleague's death (Case No. 1). The patient also denied any previous major health problem. He did not smoke whilst at work.

Physical examination revealed a well-developed man. His body temperature was $36.7^{\circ} \mathrm{C}$, pulse rate 80 beats $\cdot \mathrm{min}^{-1}$, respiratory rate 28 breaths $\cdot \mathrm{min}^{-1}$, and blood pressure 130 / $80 \mathrm{mmHg}$. Chest auscultation revealed diffuse crackles over the bilateral lung fields. The abdomen was soft and not tender, and bowel sound was normoactive. The chest radiograph revealed bilateral diffuse pulmonary infiltrates (fig. 2) The haemogram revealed that WBC count was 7,200 cells $\cdot \mathrm{mm}^{-3}, \mathrm{RBC}$ count $5.35 \times 10^{6}$ cells $\cdot \mathrm{mm}^{-3}$, Hb $16.3 \mathrm{gm} \cdot \mathrm{dL}^{-1}$, Hct $48.0 \%$, and platelet count 225,000 platelets $\cdot \mathrm{mm}^{-3}$. The arterial blood gas values, with 4 $\mathrm{L} \cdot \mathrm{min}^{-1}$ oxygen via nasal prongs, were: $\mathrm{pH} 7.41 ; \mathrm{Pa}_{\mathrm{a}} \mathrm{CO}_{2}$ $6.7 \mathrm{kPa}(49.9 \mathrm{mmHg}) ; \mathrm{Pa}_{2} \mathrm{O}_{2} 18.0 \mathrm{kPa}(135 \mathrm{mmHg})$; and $\mathrm{HCO}_{3}-26.9 \mathrm{mEq} \cdot \mathrm{L}^{-1}$. The condition of the patient improved progressively, and the follow-up chest radiograph taken 3 days after admission showed complete resolution of the pulmonary infiltrates. Pulmonary function tests, performed on September 20, showed a mild restric-

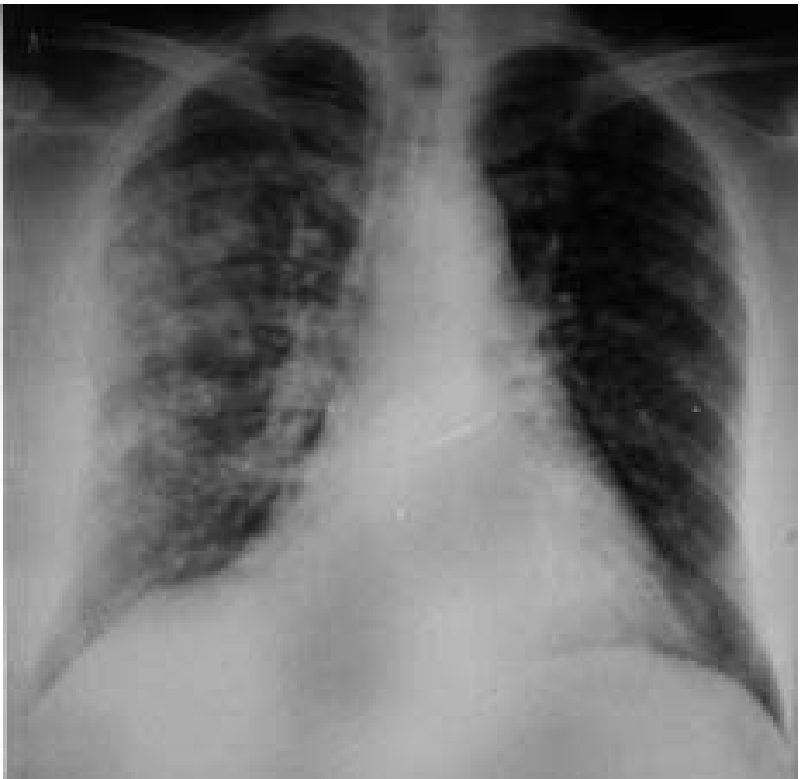

Fig. 2. - Chest radiograph of Case No. 2, on admission, demonstrating bilateral pulmonary infiltrates. The pulmonary infiltrates subsided 3 days later.

tive ventilatory defect and mild impairment of transfer factor (total lung capacity (TLC) $78 \%$ predicted; forced vital capacity (FVC) $79 \%$ pred; forced expiratory volume in one second (FEV1) 79\% pred; FEV1/FVC 89\%; transfer factor of the lung for carbon monoxide $(T \mathrm{~L}, \mathrm{CO})$ $74 \%$ pred). His prognosis was uneventful and he was discharged 7 days after admission. The pulmonary function tests performed 3 months after discharge were within normal limits (TLC $83 \%$ pred; FVC $92 \%$ pred; FEV1 $89.1 \%$ pred; FEV1/FVC $85 \%$; TL,CO $94 \%$ pred).

\section{Case No. 3}

A 22 year old man, who was a night-shift colleague of the above two men, developed chest tightness, cough and shortness of breath, in the early morning of September 13, 1995. No definite chill or fever was noted at that time. He visited a local hospital, where a chest radiograph showed diffuse pulmonary infiltrates (fig. 3), and he was treated for pneumonia. He was transferred to our hospital for further management on September 16. On admission, his body temperature was $36.5^{\circ} \mathrm{C}$, pulse rate 78 beats. $\mathrm{min}^{-1}$, respiratory rate 24 breaths $\cdot \mathrm{min}^{-1}$, and blood pressure 104/ $70 \mathrm{mmHg}$. Physical examination was unremarkable. A chest radiograph showed diffuse infiltrates in bilateral lung fields. Pulmonary function tests were performed on September 16, and also showed a mild restrictive ventilatory defect and mild impairment of transfer factor (TLC $70 \%$ pred; FVC $70 \%$ pred; FEV1 $73 \%$ pred; FEV1/ FVC $86 \%$; and TL,CO $64 \%$ pred). After admission, supportive treatments were given. The patient was discharged with improved condition 9 days after admission. This patient left the country after discharge and no follow-up pulmonary function tests were performed.

\section{Workplace}

In the room involved in the accident, two horizontal PTFE extruders were located, one of which was used 


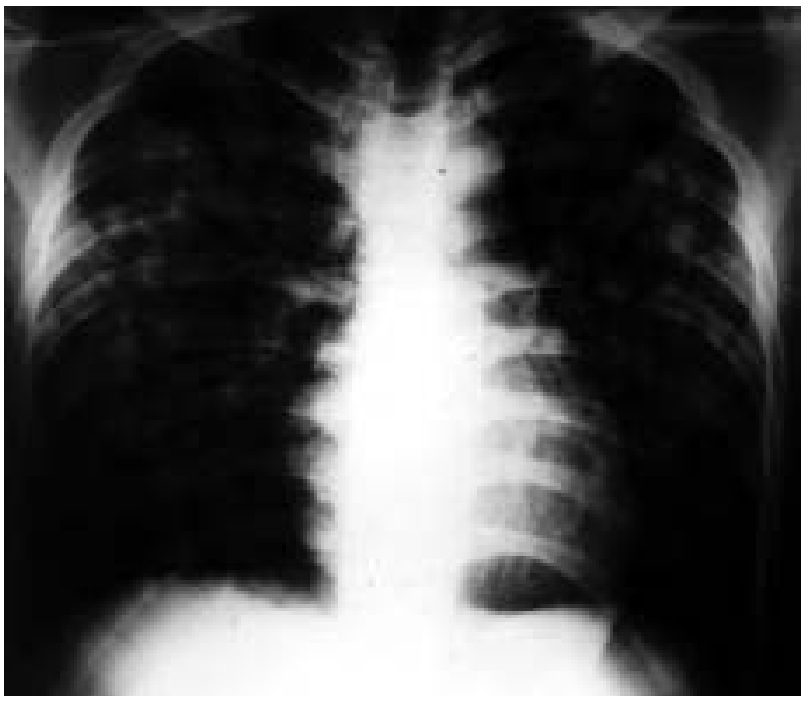

Fig. 3. - Chest radiograph of Case No. 3 revealing bilateral pulmonary infiltrates.

to produce PTFE rod on the accident date. Dry, granulated powder PTFE resins entered from the hopper and were driven by a screw-type plunger into the heating tube, in which heat and pressure compressed the powder into the PTFE rod. A water-cooling system and thermocontrol panel (temperature preset at $350^{\circ} \mathrm{C}, 380^{\circ} \mathrm{C}, 370^{\circ} \mathrm{C}$, $360^{\circ} \mathrm{C}$ and $350^{\circ} \mathrm{C}$ for 5 consecutive sections) were important features, not only for optimal rod formation but also for safety. However, when the surface temperatures of the heating sleeves were measured after the accident by using an infra-red thermometer (accuracy $\pm 0.1^{\circ} \mathrm{C}$ ), the temperatures measured were $410^{\circ} \mathrm{C}, 430^{\circ} \mathrm{C}, 430^{\circ} \mathrm{C}, 510^{\circ} \mathrm{C}$ and $430^{\circ} \mathrm{C}$. At the time of the worksite inspection after the accident, it was not known how long the thermal control system had been malfunctioning. With the exception of a ventilation fan on one wall, the workplace $(8.5 \times 4.2 \times 4.0 \mathrm{~m})$ was completely enclosed.

In the specific workplace where the accident occurred, only three workers were potentially exposed. These three workers involved in the accident were a day-shift moulder (Case No. 1, deceased), the foreman of the day-shift (Case No. 2), and a night-shift moulder (Case No. 3). The day-shift moulder was responsible for feeding the PTFE resins and stayed mainly around the feeding hopper. The foreman's duties did not restrict him to the PTFE room, and included monitoring other worksites, and cutting and packing PTFE rods. The night-shift moulder, although remaining mainly around the hopper, was also responsible for other jobs, such as cutting and packing. Based upon job description alone, it is likely that the foreman and the night-shift moulder, who recovered after treatment, were exposed to a smaller dose.

\section{Discussion}

We have presented the cases of three patients with acute pulmonary oedema, including one with fatal outcome, caused by inhalation of fumes from heated PTFE. The pyrolytic products of PTFE are considered toxic to human lungs. It has been known since 1951 [2] that the exposure to fumes of PTFE can cause a fever reaction known as polymer fume fever, which consists of fever, chest discomfort, and malaise. Since then, only a few cases of pulmonary oedema after exposure to fumes from PTFE have been reported [3, 7-9], and all of these patients recovered within a few days after treatment.

When PTFE resins are subjected to a relatively high temperature, toxic pyrolytic products evolve in a temperature- and oxygen-dependent manner $[1,10]$. The toxi-city of these decomposition products varies widely [11-13], from the slightly toxic tetrafluoroethylene monomer $\left(\mathrm{CF}_{2}=\mathrm{CF}_{2}\right.$; median lethal concentration (LC50) $=40,000$ parts per million (ppm) for $4 \mathrm{~h}$ exposure of rats) to the highly toxic compounds, such as octafluoroisobutylene $\left(\left(\mathrm{CF}_{3}\right)_{2} \mathrm{C}=\mathrm{CF}\right)$, hydrogen fluoride $(\mathrm{HF})$ and carbonyl fluoride $\left(\mathrm{COF}_{2}\right)$. In an animal study [14], there were no clinical symptoms or lung alterations in rats exposed to the pyrolytic products of PTFE at temperatures below $425^{\circ} \mathrm{C}$. However, at $450^{\circ} \mathrm{C}$, rats revealed severe respiratory difficulty, pulmonary oedema, haemorrhage, and necrosis of the tracheobronchial epithelium. This suggests that exposure to pyrolytic products from heated PTFE at high temperature can cause severe lung injury.

As noted above, the documented operating temperature of the PTFE extruder exceeded design specifications. It is not known when the excessive temperature began. However, it is believed that the high temperature during the manufacturing process caused PTFE resins to pyrolyse $[9,10]$, and that the pyrolytic products released caused acute pulmonary oedema in these workers $[7,8]$. Also, as noted above, a dose-response relationship was apparent, with the most heavily exposed worker (the day-shift moulder) becoming a fatality.

The acute pulmonary oedema in the deceased patient was very severe, as was manifested by total opacity of both lungs on chest radiography, and severe dehydration, with shock, and haemoconcentration. This suggests that there was very severe pulmonary capillary injury and fluid leakage from the capillaries to the alveolar space after inhalation of the fumes from the heated PTFE at high temperature $\left(>450^{\circ} \mathrm{C}\right)$. The severe lung injury, with subsequent fulminant fluid leakage into the pulmonary capillaries, resulted in refractory hypoxaemia, profound shock and death, even after intensive treatment. The fact that the patient developed respiratory distress a few hours after work was compatible with a typical delayed onset of inhalation pulmonary injury.

This is the first report describing fatal acute pulmonary oedema in a worker exposed to pyrolytic products of polytetrafluoroethylene in a plastic extruding operation. Since polytetrafluoroethylene extrusion is a common operation in plastic industries, special precautions should be taken to prevent this potentially fatal occupational disease due to exposure to the pyrolytic products of this material.

\section{References}

1. Parmeggiani L. Polyfluorines. 3rd edn. Encyclopaedia of Occupational Health and Safety. Geneva, Switzerland, International Labour Organization, 1983; 17621763. 
2. Harris KD. Polymer fume fever. Lancet 1951; ii: 1008 1011

3. Lewis C, Kerby G. An epidemic of polymer fume fever. J Am Med Assoc 1965; 191: 103-106.

4. Williams N, Smith FK. Polymer fume fever: an elusive diagnosis. J Am Med Assoc 1972; 219: 1587-1589.

5. Williams N, Atkinson GW, Patchefsky AS. Polymer fume fever: not so benign. J Occup Med 1974; 16: 519-522.

6. Albrecht WN, Bryant CJ. Polymer fume fever associated with smoking and use of a mold-release spray containing polytetrafluoroethylene. J Occup Med 1987; 29: 817-819.

7. Robbins J, Robert WL. Pulmonary edema from Teflon fumes: report of a case. N Engl J Med 1964; 271: 360-361.

8. Elizabeth AE. Pulmonary edema after inhalation of fumes from polytetrafluoroethylene (PTFE). J Occup Med 1973; 15: 599-601.

9. Brubaker RE. Pulmonary problems associated with the use of polytetrafluoroethylene. J Occup Med 1977; 19: 693-695.

10. Arito H, Soda R. Pyrolysis products of polytetrafluoroethylene and polyfluoroethylenepropylene with reference to inhalation toxicity. Ann Occup Hyg 1977; 20: 247-255.

11. Melvin T, Okawa S. Occupational health case reports. No. 7. Teflon. J Occup Med 1974; 16: 350-355.

12. Darmer KI, Haun CC, Macewen JD. The acute inhalation toxicology of chlorine pentafluoride. Am Ind Hyg Assoc J 1972; 32: 661-668.

13. Scheel LD, Lane WC, Coleman WE. The toxicity of polytetrafluoroethylene pyrolysis products, including carbonyl fluoride and a reaction product, silicon tetrafluoride. Am Ind Hyg Assoc J 1968; 29: 41-48.

14. Lee KP, Zapp JA, Sarver JW. Ultrastructural alterations of rat lung exposed to pyrolysis products of polytetrafluoroethylene (PTFE, Teflon). Lab Invest 1976; 35: 152-160. 